\title{
Yersinia ruckeri, the causative agent of enteric redmouth disease in fish
}

\author{
Gokhlesh Kumar*, Simon Menanteau-Ledouble, Mona Saleh and Mansour El-Matbouli[D
}

\begin{abstract}
Enteric redmouth disease (ERM) is a serious septicemic bacterial disease of salmonid fish species. It is caused by Yersinia ruckeri, a Gram-negative rod-shaped enterobacterium. It has a wide host range, broad geographical distribution, and causes significant economic losses in the fish aquaculture industry. The disease gets its name from the subcutaneous hemorrhages, it can cause at the corners of the mouth and in gums and tongue. Other clinical signs include exophthalmia, darkening of the skin, splenomegaly and inflammation of the lower intestine with accumulation of thick yellow fluid. The bacterium enters the fish via the secondary gill lamellae and from there it spreads to the blood and internal organs. Y. ruckeri can be detected by conventional biochemical, serological and molecular methods. Its genome is $3.7 \mathrm{Mb}$ with 3406-3530 coding sequences. Several important virulence factors of Y. ruckeri have been discovered, including haemolyin YhIA and metalloprotease Yrp1. Both non-specific and specific immune responses of fish during the course of $Y$. ruckeri infection have been well characterized. Several methods of vaccination have been developed for controlling both biotype 1 and biotype 2 Y. ruckeri strains in fish. This review summarizes the current state of knowledge regarding enteric redmouth disease and Y. ruckeri: diagnosis, genome, virulence factors, interaction with the host immune responses, and the development of vaccines against this pathogen.
\end{abstract}

\section{Table of contents}

1. Introduction

2. Identification and classification

3. Clinical signs and pathology of the disease

4. Distribution of Yersinia ruckeri

5. Transmission and epidemiology

6. Route of entry and spread

7. Genome

8. Diagnosis

9. Virulence factors

10. Host immune response

11. Control/treatment

11.1 Antibiotherapy

11.2 Probiotics

11.3 Vaccination

12. Conclusions

13. Abbreviations

14. Competing interests

15. Authors' contributions

* Correspondence: gokhlesh.kumar@vetmeduni.ac.at

Clinical Division of Fish Medicine, Department for Farm Animals and Veterinary Public Health, University of Veterinary Medicine, Vienna, Austria
16. Acknowledgements

17. References

\section{Introduction}

Fish constitute a major source of protein, fatty acids, vitamins, minerals and essential micronutrients for an expanding segment of the world population. Consequently, aquaculture is the fastest growing food production sector and accounts for approximately $50 \%$ of the fish consumed worldwide [1]. Disease outbreaks have become a major constraint to the expansion of aquaculture and have a significant impact on the economic development of many countries. Enteric redmouth disease (ERM, yersiniosis) is one of the most important diseases of salmonids and leads to significant economic losses [2]. The disease is caused by Yersinia ruckeri, a Gramnegative rod-shaped enterobacterium, which was first isolated from rainbow trout (Oncorhynchus mykiss) in the Hagerman Valley of Idaho, USA [3] and is currently found throughout North and South America, Europe, Australia, South Africa, the Middle East and China $[4,5]$. Although infections have been reported in other fish species, rainbow trout are especially susceptible to ERM 
[2-4]. Rainbow trout are fast growing and robust under farming conditions, and thus are the most widely farmed salmonid fish [1]. Herein, we review the latest scientific developments on $Y$. ruckeri, including the present distribution and diagnosis of ERM, the route of entry of $Y$. ruckeri into the fish, its genome, virulence factors, interactions with the host and immune responses, and methods to control yersiniosis.

\section{Identification and classification}

Yersinia is a genus of Gram-negative, rod-shaped, facultative anaerobes within the family Enterobacteriaceae. Yersinia comprises several pathogenic species, which cause diseases in humans and other animals, including fish. Yersinia ruckeri is the causative agent of enteric redmouth disease in various species of salmonids worldwide. It was described from rainbow trout in the Hagerman Valley of Idaho, USA in the 1950s [3]. The Y. ruckeri bacillus is approximately $0.75 \mu \mathrm{m}$ in diameter and $1-3 \mu \mathrm{m}$ in length. Y. ruckeri has a 3.7Mb genome, with a $\sim 47 \% \mathrm{G}+\mathrm{C}$ ratio [6,7], the same as other Yersinia species [7,8]. Highthroughput DNA sequencing of Yersinia species has confirmed that $Y$. ruckeri shares the same core set of genes with the other members of the genus [9].

Different strains of $Y$. ruckeri have been reported and categorized on the basis of serotypes, biotypes and outer-membrane protein types. In 1993, the typing scheme was updated and species were further subdivided into four serotypes with different subgroups: Serotype $\mathrm{O} 1$ is subdivided into two subgroups O1a (serovar I) and O1b (serovar III) and serotype O2 (serovar II) into three subgroups $\mathrm{O} 2 \mathrm{a}, \mathrm{O} 2 \mathrm{~b}$ and $\mathrm{O} 2 \mathrm{c}$. The remaining serotypes are designated as serotype $\mathrm{O} 3$ (serovar $\mathrm{V}$ ) and serotype O4 (serovar VI) [10]. The vast majority of epizootics in salmonids is caused by motile serotype O1a [10].

Strains of $Y$. ruckeri have also been subdivided into two biotypes. Strains of biotype 1 are positive for motility and lipase secretion, whereas strains of biotype 2 are negative for both tests $[2,4]$. However, the ability to secrete lipase appears to have little relevance to the virulence of $Y$. ruckeri during the natural infection [11]. Y. ruckeri is characterized biochemically as glucose-fermentative, catalasepositive, nitrate-reductive, oxidase-negative, with the ability to secrete b-galactosidase, lysine and ornithine decarboxylases but neither hydrogen sulfide nor indole $[2,4]$.

The genetic structure and variations within $Y$. ruckeri have been investigated using molecular tools including multilocus enzyme electrophoresis, pulsed-field gel electrophoresis (PFGE), fatty acid methyl ester profiles, ribotypes and interspersed repetitive sequences-PCR. These have shown that O1a strains of $Y$. ruckeri have high levels of genetic homogeneity [12,13]. Bastardo et al. [14] investigated the diversity and evolutionary relationships among a geographically and temporally diverse collection of $Y$. ruckeri strains using a multilocus sequence typing scheme. These authors suggested the existence of two major clonal complexes (CC1 and CC2) within the $Y$. ruckeri population structure. They support the 'epidemic' model of clonal expansion, in which populations of well-adapted clones explode to be widely distributed. Genetic and antigenic differences have been found between biotype 1 and biotype 2 strains, using $16 \mathrm{~S}$ rRNA sequence analysis, genotyping (including ERIC-PCR and (GTG) $)_{5}$-PCR), and Western blot analysis $[15,16]$. Furthermore, Welch [17] developed a novel PCR-based assay to detect mutant alleles in strains of $Y$. ruckeri using fliR gene primers, restriction enzyme digestion and sequencing of the resulting fragments. This assay identified four mutant alleles in biotype 2 strains of $Y$. ruckeri that are presently circulating in Europe and the United States, and which can cause outbreaks in vaccinated fish.

\section{Clinical signs and pathology of the disease}

ERM can affect fish from all age classes but it is most acute in young fish (fry and fingerlings). The disease appears as a more chronic condition in older/larger fish. Disease outbreaks start with low level mortalities that are sustained over time, resulting in high cumulative stock losses $[2,4]$. Changes in fish behavior may be observed, including swimming near the surface, lethargic movements and loss of appetite. Other signs of disease include exophthalmia and darkening of the skin, and subcutaneous hemorrhages in and around the mouth and throat, which give the disease its common name. Petechial hemorrhages may occur on the surfaces of the liver, pancreas, pyloric caeca, swim bladder and in the lateral muscles. The spleen is often enlarged and can be almost black in color (Figure 1), and the lower intestine can become reddened and filled with an opaque, yellowish fluid $[2,4]$.

Histopathological examination shows general septicaemia with inflammation in most organs, and particularly kidney, spleen, liver, heart, gills and in areas with petechial haemorrhage. Pathological changes in the gills, including hyperemia, oedema and desquamation of the epithelial cells in the secondary lamellae have been described $[2,4,18]$. Focal areas of necrosis can be present in the spleen (Figure 2A), kidney (Figure 2B) and liver. In the kidney, degenerated renal tubules, glomerular nephritis and a marked increase in melano-macrophages may be observed $[2,4,18]$.

\section{Distribution of $Y$. ruckeri}

Since the first report of $Y$. ruckeri infection in rainbow trout in the USA [3], the pathogen has been isolated from multiple other fish species worldwide, including Canada, Europe, South America, the Middle East, China, 


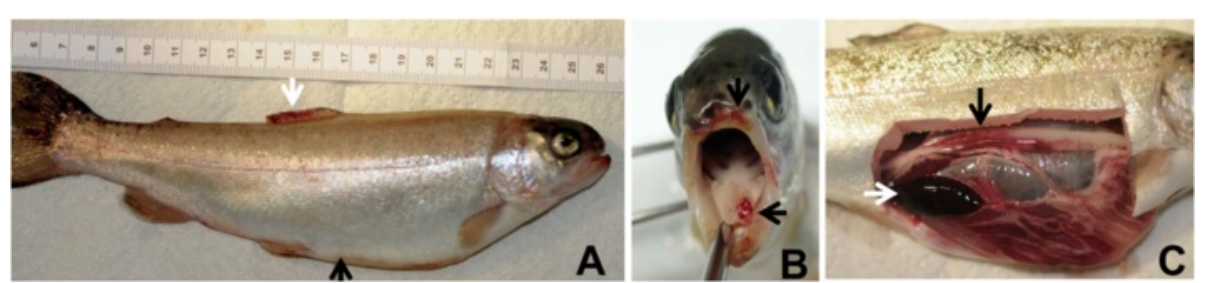

Figure 1 Rainbow trout showing clinical signs of enteric redmouth disease. A: darkening of the skin, enlarged abdominal valley (black arrow), and hemorrhages in the dorsal fin (white arrow). B: hemorrhages in and around the mouth (arrows). C: enlarged and black spleen (white arrow), and reddened intestine (black arrow).

India and Australia [4,5,19]. Additionally, Y. ruckeri has been isolated from animals other than fish, including muskrat (Ondatra zibethicus), kestrel (Falco spp.), sea gulls (Laridae), turtles (Cheloniidae) and humans $[4,20,21]$. These numerous reports demonstrate that $Y$. ruckeri has a wide host range and geographical distribution, and can cause both epizootics and zoonosis.

\section{Transmission and epidemiology}

$Y$. ruckeri infections can be transmitted by direct contact between infected and non-infected fish. A carrier state for $Y$. ruckeri was demonstrated, where infectious fish can survive 2 months after both experimental [4] and natural infections $[4,22]$. Busch and Lingg [23] verified that up to $25 \%$ of a rainbow trout population could carry $Y$. ruckeri in the lower intestine. The bacteria can then be released when the carrier fish become stressed. For example, it was observed that carriers transmitted $Y$. ruckeri to clinically healthy fish when the temperature was raised to $25{ }^{\circ} \mathrm{C}$, but no transmission occurred from unstressed carrier fish [24]. Shedding of the bacterium in the feces is also likely to play an important role in transmission, and $Y$. ruckeri can survive at least 4 months outside the host [23]. The bacterial cells use either pili or flagella to move along surfaces to link with other bacteria and form or enlarge microcolonies [25,26]. The over-expression of flagellar proteins is a phenotypic characteristic of bacteria associated with high adhesiveness and is essential to initiate development of biofilms. It is now well recognized that the formation of biofilms is an important feature of the survival of bacteria on surfaces and in sediments in aquatic environments [26,27]. Coquet et al. [27] isolated a Y. ruckeri strain that was able to form biofilms on the solid supports frequently

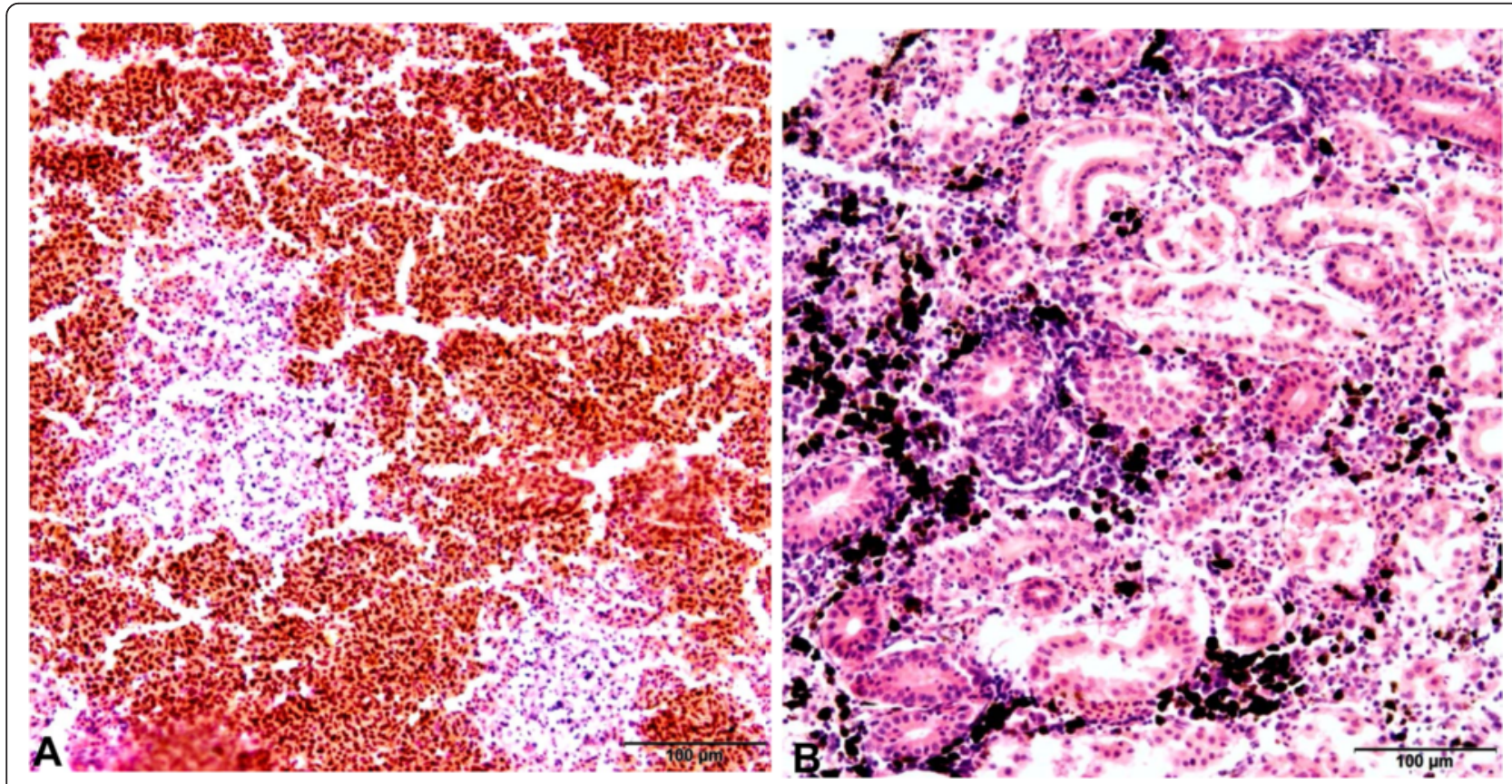

Figure 2 Histological sections of spleen and kidney organs of rainbow trout infected with $Y$. ruckeri. A: multifocal necrosis can be seen in the spleen. B: degeneration of interstitial tissue and a marked increase in melano-macrophages can be seen in the kidney. Sections were stained with haematoxylin and eosin (H\&E). 
found in fish farm tanks. These biofilms are reported to be a source of recurrent infection in rainbow trout facilities [4,27]. The spread of $Y$. ruckeri has also been linked to putative vectors, which include aquatic invertebrates and birds [20]. While vertical transmission from mother to progeny has not been well studied, $Y$. ruckeri has been recovered from disinfected non-fertilized eggs of Chinook salmon (Oncorhynchus tshawytscha), whose offspring experienced low mortalities from fertilization to 12 weeks on feed [28]. Furthermore, the recent discovery of Y. ruckeri DNA in unfertilized eggs and ovarian fluid of Chinook salmon suggests that the pathogen could be transmitted vertically. However, this study was unable to verify the occurrence of bacterial cells within the chorion of the egg [28].

\section{Route of entry and spread}

Histological examination of rainbow trout experimentally infected with $Y$. ruckeri indicated that gills are an important portal of entry for $Y$. ruckeri. Thereafter, $Y$. ruckeri spreads to the other organs [18]. This spread was recently visualized in organs of rainbow trout using optical projection tomography and immunohistochemistry [29]. The authors suggested that $Y$. ruckeri initially infects the secondary gill lamellae, then spreads to the blood system via the gill pavement cells, as rapidly as $1 \mathrm{~min}$ post infection (mpi). It could be detected in the lumen of the intestine at $30 \mathrm{mpi}$, in the kidney at 3 days post infection (dpi), and in the liver, spleen, brain and heart at $7 \mathrm{dpi}$. Y. ruckeri was no longer detectable in the liver, spleen, brain and heart at $21 \mathrm{dpi}$ [29].

\section{Genome}

Annotated whole genome sequences of two strains of $Y$. ruckeri are currently available: the motile CSF007-82 strain, isolated from diseased rainbow trout and the motile $\mathrm{O} 1 \mathrm{~b}$ 37551 strain, isolated from vaccinated Atlantic salmon (Salmo salar) (GenBank accession numbers PRJEB6967 and JPFO00000000, respectively) [7,30]. The genome of CSF007-82 is $3799036 \mathrm{bp}$ and contains 3530 coding sequences (CDS), 80 tRNA and 7 ribosomal operons, while that of O1b 37551 is 3775486 bp and contains 3,406 CDS, 56 tRNA and 4 rRNA genes [7,30]. The availability of these whole genomes is contributing to better understanding of pathogenesis and virulence factors, facilitating identification of mutations and construction of new targets for vaccines. However, whole genome sequences of non-motile $Y$. ruckeri strains from different geographical locations are still needed to gain insight into the differences between motile and non-motile strains.

\section{Diagnosis}

Multiple diagnostic assays have been developed for $Y$. ruckeri, including culturing, serological tests and molecular biological techniques [4]. Y. ruckeri has been isolated using Tryptic soy agar, Columbia blood agar and MacConkey agar $[2,4,31,32]$. While $Y$. ruckeri can grow at a wide range of temperatures, its thermal optimum is $20-28{ }^{\circ} \mathrm{C}[2,4] . Y$. ruckeri can be detected using ELISA, agglutination and immunofluorescence antibodies [33]. Molecular detection techniques include restriction fragment length polymorphism [34], loop-mediated isothermal amplification (LAMP) [35] and polymerase chain reaction (PCR) $[32,36,37]$. PCRbased amplification of the $16 \mathrm{~S}$ rRNA gene can detect $Y$. ruckeri in tissues of infected fish [32,36,37]. A LAMP assay was optimized by Saleh et al. [35] and amplifies the yruI/ yruR gene, which encodes the $Y$. ruckeri quorum sensing system. This ERM-LAMP assay is sensitive, rapid and the amplification products can be detected by visual inspection or gel electrophoresis (Figure 3).

The PCR method described by Gibello et al. [32] has the advantage of being able to detect low levels of $Y$. ruckeri, and thus provide the possibility to detect asymptomatic carriers; essential to avoid transmission and spread of ERM. PCR detection of Y. ruckeri in the blood of rainbow trout was described by Altinok et al. [37]. The use of blood samples is a non-lethal sampling method and permits repetitive sampling of individual fish. Other nonlethal methods include culture of feces and biopsy of head kidney by dorsocaudal aspiration of the kidney tissue [38]. Improvements in specificity of both conventional and quantitative PCR (qPCR) assay have been attained using other candidate genes [39-41]. Bastardo et al. [42] recently described a qPCR method based on the recombinant protein A (recA) gene. Gold nanoparticle-based assays are an emerging technology, which may become a powerful tool for rapid, direct and sensitive detection of unamplified $Y$. ruckeri nucleic acids in clinical samples. In nanoparticle-based assays, DNA or RNA hybridizes with pathogen-specific probes that are attached to the surface of the gold nanoparticles. Hybridization occurs at a determined temperature and time, and results in aggregation of the nanoparticles and a concomitant red to blue color change [43].

\section{Virulence factors}

Several virulence mechanisms of $Y$. ruckeri have been identified, and found to differ with the geographical origin of the isolate. Several extra-cellular products (ECP) have been shown to reproduce the clinical signs associated with the hemorrhagic form of the disease when injected into their host [10]. Multiple molecules are known to contribute to the virulence of these ECP, for example: the iron-regulated Serratia-like haemolysin YhlA, which has cytolytic and haemolytic activity [44], an azocasein protease [45], and the $47 \mathrm{kDa}$ metalloprotease Yrp1, which has a wide range of targets and is particularly efficacious at degrading fibronectin, actin and 

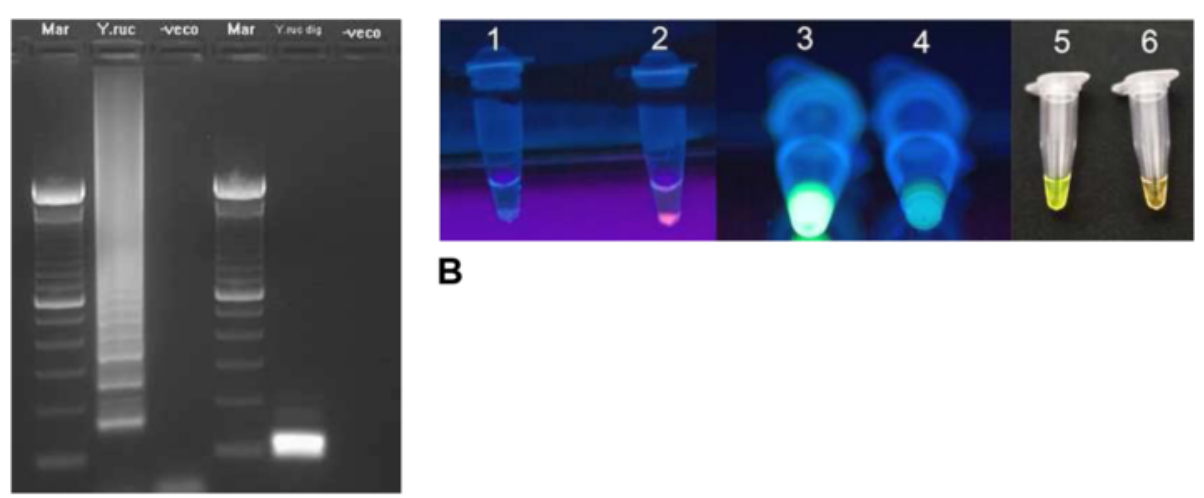

B

A

Figure 3 Detection methods for Yersinia ruckeri using loop-mediated isothermal amplification method. A: Agarose gel showing ERMLAMP products of Y. ruckeri; Lane mar: 100 bp DNA ladder, lane Y. ruc: amplified Y. ruckeri LAMP product, lane Y. ruc dig: Hph I digested Y. ruckeri LAMP products of 87 and 108 bp, and lane veco: negative control. B: Visual detection of ERM LAMP products using SYBR Green I stain 1: 1: Negative control reaction using Rox- labelled probe, there is neither pellet nor red fluorescence, 2: positive control reaction using Rox- labelled probe, the pellet emitted red fluorescence; 3: positive sample by using FDR, emitted strong green fluorescence when exposed to UV light; 4: negative sample by using FDR, did not emit strong green fluorescence under UV light; 5: positive sample with green color using SYBR green I stain; 6: negative sample with orange color using SYBR green I stain (Image from Saleh et al. [35] with permission).

myosin [46,47]. Recently, yrpA and yrpB have been demonstrated to be induced in the gut of rainbow trout [48]. In addition, genes involved in the catecholate siderophore ruckerbactin iron acquisition system were shown to be over-expressed by the bacterium during the infection process in fish. Inactivation of the corresponding gene led to a hundred-fold increase in the $\mathrm{LD}_{50}$ of the bacterium [49]. Heat sensitive factor (HSF) produced by the alkylsulphatase enzyme YraS has been proposed as a virulence factor [50], and a differential culture medium, using Coomassie Brilliant Blue has been developed to identify strains that carry this factor [51]. However, recent findings have contradicted these results and suggested that HSF might not be required for $Y$. ruckeri virulence [52]. Similarly, the cdsAB operon was initially identified through in vitro expression technology [49] and has been shown to be required for uptake of Lcysteine by the bacterium [53]. However, despite Lcysteine being present in fish serum, mutations in the cdsAB operon failed to impact the growth of Y. ruckeri, raising questions about the necessity of the cdsAB operon [54].

Finally, as is often the case in microbial pathogens, the expression of these virulence factors appears tightly regulated and linked with both the availability of iron [44] and the concentration of auto-inducing molecules $[41,55]$. BarA-UvrY is a regulator identified in Y. ruckeri [55] and has homologs in other enterobacteria. BarAUvrY is involved in resistance to oxidative killing, and the invasion of host cells. However, on the contrary to observations in other enterobacteria, mutations in BarAUvrY did not impact the growth of $Y$. ruckeri under iron-limited conditions [56]. More research is still needed to identify novel virulence genes and to understand the full pathogenic mechanisms of $Y$. ruckeri during the infection process in the fish.

\section{Host immune response}

Non-specific and specific immune responses of fish against $Y$. ruckeri strains have been studied extensively. For example, both $\mathrm{O}$-antigen and formalin-inactivated $Y$. ruckeri cells induced an immune response in rainbow trout $[57,58]$, producing peak levels of antibody in the spleen at 14 days post exposure (dpe) and overall maximum titer at 28 dpe [57]. Similarly, intra-peritoneal booster doses of $Y$. ruckeri bacterin induced a significant immune response in rainbow trout at 146 days post injection [58]. Phagocytic cells, such as neutrophils and macrophages, are an important part of the fish host immune system, and an inflammatory response to $Y$. ruckeri has been observed in the body cavity of rainbow trout [59]. Gene expression levels of CXCd, cytokine, chemokine, interleukin, cell receptor, immunoglobulin, SCOS and CISH genes have been measured in rainbow trout in response to Y. ruckeri biotype 1 strains [60-64] and $Y$. ruckeri biotype 2 strains using quantitative realtime PCR $[65,66]$. Recent discoveries suggest production of specific antibodies against $Y$. ruckeri may play a role in protection against disease [63]. Serum amyloid A, which belongs to a highly conserved group of apolipoproteins, is considered to be an important innate immune molecule in rainbow trout during the course of $Y$. ruckeri infection [67]. All these studies contribute to our understanding of how the innate and adaptive immune systems in rainbow trout respond to both primary infection (first infection) and re-infection (secondary infection). It is 
worthy of note that all of these studies were based on mRNA expression, which may not always accurately reflect protein expression and biochemical changes [68]. Mechanisms of biochemical changes in the organs of fish infected with strains of $Y$. ruckeri biotypes 1 and 2 at the proteomics level still need to be investigated, both to understand the proteomic background for observed proteomic changes, and to elucidate the mechanism of action of the proteins whose expression differs between the biotypes.

\section{Control/treatment}

\subsection{Antibiotherapy}

As is often the case with fish bacterial pathogens, postinfection treatment relies mostly on the use of antibiotics. Unfortunately, only a limited spectrum of compounds is routinely used [69]: amoxicillin; oxolonic acid; oxytetracycline; sulphadiazine in combination with trimethroprim and, more recently, florfenicol [70]. This narrow range of options may facilitate the emergence of antibiotic resistance [71]. Screening of $Y$. ruckeri isolates has shown that only 1 out of 50 was resistant to florfenicol [70]. Similarly, a more recent review suggested that most European isolates are still widely responsive to antibiotherapy [72]. While a $\beta$-lactamase gene has been discovered on the chromosome of $Y$. ruckeri [73], there is evidence that this gene is not likely to be expressed at high levels [74]. In vitro testing has, however, shown that $Y$. ruckeri readily develops resistance against oxolinic acid, oxytetracycline and potentiated sulphonamide [75]. Finally, and more anecdotally, $Y$. ruckeri is both a natural producer of and naturally resistant to the antibiotic holomycin [76].

\subsection{Probiotics}

Concern about the development of antibiotic resistance has spurred research into alternative methods for controlling bacteria, in particular, beneficial probiotic bacteria and yeast [77]. Some success has been demonstrated for the use of probiotics to fight $Y$. ruckeri: oral administration of Bacillus subtilis and Bacillus licheniformis protects rainbow trout against subsequent infections [78]. The authors hypothesized that this protection was due to either antimicrobial secretions by the bacterium or to its immunostimulating effect. This later hypothesis was supported by data that showed that injection of cell wall components of probiotic strains of B. subtilis and outer membrane components including LPS of Aeromonas sobria, were also protective [79].

Dietary supplementation with Bacillus sp., and Aeromonas sobria, was confirmed as protective by Brunt et al. [80]: it reduced mortalities from $80 \%$ in the control to 0\% (Bacillus sp. treatment) and 6\% (A. sobria treatment). Similarly, Enterobacter cloacae fed alongside
Bacillus mojavensis was shown to reduce mortalities from Y. ruckeri challenge from 65 to $0.8 \%$ [81].

Feed supplementation with Carnobacterium maltaromaticum B26 and Carnobacterium divergens isolated from the normal intestinal microbiota of rainbow trout were found to be protective against further Y. ruckeri infections [82]. Interestingly, studies by Robertson et al. [83] confirmed the protective action of Carnobacterium sp. but found no antagonistic activity in vivo, suggesting that, as seems to be the case for $B$. subtilis, protection is achieved by stimulation of host defense rather than direct anti-microbial effect.

In addition, Lactobacillus lactis was shown to be antagonistic to Y. ruckeri and, as with Lactobacillus fermentum, significantly reduces adhesion of the pathogen to fish mucus [84]. Comparable results were reported by Sica et al. [85] who screened 12 lactic acid bacteria and found that $60 \%$ of them displayed competitive exclusion against $Y$. ruckeri.

Recently, it was reported that feeding fish with a plant-based diet modified the composition of their gut microflora, and affected their immune response to $Y$. ruckeri [86], suggesting a prebiotic effect. This however did not correlate to a significant difference in mortalities during that trial.

Jaafar et al. [87] investigated the effect of two supplements: organic acids and a combination of $\beta$-glucan alongside mannan-oligosaccharides, nucleotides, lactic acid bacteria, and vitamins $\mathrm{C}$ and $\mathrm{E}$. The supplements were tested separately and in conjunction, but were found not to have a significant effect on survival of fish exposed to $Y$. ruckeri.

\subsection{Vaccination}

The significant economic losses in salmonid fish aquaculture can be controlled to some extent by use of vaccinations. ERM was one of the first fish diseases for which an effective commercial vaccine was developed $[2,88]$. The vaccine utilizes monovalent, inactivated whole cell suspensions of $Y$. ruckeri serotype O1 biotype 1, which can be administered to fish by several routes, e.g. immersion, injection and oral. It provides good levels of protection against $Y$. ruckeri biotype 1 strains [89-93], as summarized in Table 1 . New vaccines have been developed that are based on the $Y$. ruckeri Yrp1 protease, aroA gene, extracellular product and lipopolysaccharide and these provide good protection against $Y$. ruckeri biotype 1 strains [94-96]. However, Y. ruckeri biotype 2 strains are harder to combat and have been responsible for disease outbreaks in fish that had been vaccinated against biotype 1 strains; thus monovalent vaccines fail to induce protection against biotype 2 infection [15,31]. A bivalent vaccine was developed using formalin inactivated biotypes 1 and biotype $2 Y$. ruckeri strains, and 
Table 1 Experimental vaccine trials using a variety of antigen-preparation methods and their protection in fish following experimental infection

\begin{tabular}{|c|c|c|c|c|c|}
\hline Antigens & Routes & Fish species & Challenge strains & RPS (\%) & References \\
\hline $\begin{array}{l}\text { Formalin inactivated high } \mathrm{pH} \\
\text { Y. ruckeri O1, strain } \mathrm{Y}-11\end{array}$ & Immersion & Rainbow trout & Y. ruckeri O1, strain Y-12 & $83-96$ & {$[89]$} \\
\hline $\begin{array}{l}\text { Yrp1 protease toxoid of } Y \text {. ruckeri, } \\
\text { strain 150RI4 }\end{array}$ & i.p. & Rainbow trout & Y. ruckeri, strain 150 & 79 & {$[46]$} \\
\hline $\begin{array}{l}\text { Live attenuated Y. ruckeri O1, } \\
\text { strain } 21102\end{array}$ & i.p. & Rainbow trout & Y. ruckeri O1, strain 21102 & 90 & {$[94]$} \\
\hline $\begin{array}{l}\text { Formalin inactivated } Y \text {. ruckeri } \mathrm{O} 1 \text {, } \\
\text { biotype } 1\end{array}$ & Bath & Rainbow trout & Y. ruckeri O1, strain 392/2003 & $75-76.9$ & {$[61]$} \\
\hline Extracellular product of $Y$. ruckeri & Immersion & Rainbow trout & Y. ruckeri & $74-81.4$ & {$[95]$} \\
\hline $\begin{array}{l}\text { Formalin inactivated } Y \text {. ruckeri } 01 \mathrm{~b} \\
\text { biotype } 1 \text { (Yersinivac-B) }\end{array}$ & Immersion & Atlantic salmon & Y. ruckeri O1b, strain TCFB 2282 & 37 & {$[91]$} \\
\hline Trypsinated Yersinivac-B & Immersion & Atlantic salmon & Y. ruckeri O1b, strain TCFB 2282 & 55.6 & {$[91]$} \\
\hline $\begin{array}{l}\text { Formalin inactivated } Y \text {. ruckeri } \\
\text { serotype } 01 \text {, biotype } 1 \times \text { biotype } 2 \text { (EX5) }\end{array}$ & Immersion & Rainbow trout & $\begin{array}{l}\text { Y. ruckeri O1, strains EX5, 58669, } \\
\text { G1S1, DenA, BAS2A }\end{array}$ & $87-100$ & {$[16]$} \\
\hline $\begin{array}{l}\text { Formalin inactivated } Y \text {. ruckeri } \\
\text { serotype } 01 \text {, biotype } 1 \times \text { biotype } 2 \text { (EX5) }\end{array}$ & Immersion and i.p. & Rainbow trout & $\begin{array}{l}\text { Y. ruckeri O1, biotype 2, strain } \\
\text { 100415-1/4 }\end{array}$ & 100 & {$[97]$} \\
\hline $\begin{array}{l}\text { Formalin inactivated Y. ruckeri biotype 1, } \\
\text { strain Hagerman }\end{array}$ & Immersion & Rainbow trout & $\begin{array}{l}\text { Y. ruckeri O1, biotype 2, strain } \\
\text { 100415-1/4 }\end{array}$ & 29.5 & {$[64]$} \\
\hline $\begin{array}{l}\text { Recombinant flagellin protein of } \\
\text { Y. ruckeri biotype } 1 \text { BA } 19\end{array}$ & i.p. & Rainbow trout & $\begin{array}{l}\text { Y. ruckeri biotype } 1 \text { YR1 and } \\
\text { biotype } 2 \text { R1 }\end{array}$ & $68-72$ & {$[99]$} \\
\hline $\begin{array}{l}\text { Formalin inactivated Y. ruckeri biotype 1, } \\
\text { strain KC291153 }\end{array}$ & $\begin{array}{l}\text { Immersion with } \\
\text { montanide adjuvant }\end{array}$ & Rainbow trout & Y. ruckeri biotype 1, strain KC291153 & $93.8-100$ & {$[82]$} \\
\hline Lipopolysaccharide of $Y$. ruckeri & i.p. & Rainbow trout & Y. ruckeri & $77.4-85.1$ & {$[94]$} \\
\hline $\begin{array}{l}\text { Formalin inactivated } Y \text {. ruckeri biotype 1, } \\
\text { strain Hagerman }\end{array}$ & Oral and anal & Rainbow trout & Y. ruckeri O1, biotype 1, strain 392 & 100 & {$[93]$} \\
\hline
\end{tabular}

i.pc intraperitoneal injection, RPS relative percentage survival.

provides good protection against the biotype 2 strains $[16,97]$. cDNA microarray analyses of gill tissues from unvaccinated and vaccinated Atlantic salmon (Salmo salar) challenged with $Y$. ruckeri O1b biotype 1, have led to detection of genes and biosignatures which may be useful as predictive indicators of vaccine success. These targets include: non-protective/pathological response genes (cathelicidin, C-type lection and collagenase), vaccine-induced protective genes (immunoglobulin heavy chain, selenoprotein, 60S ribosomal protein L37 and unknown) and transcriptional biosignature of predominantly immune-relevant genes including hepcidin, immunoglobulin mu heavy chain, mylelin and lymphocyte protein. Detection of these bioindicators demonstrates that there is a range of potential targets for future vaccine development [98].

\section{Conclusions}

Y. ruckeri causes significant economic losses, particularly in salmonid aquaculture. Two whole genome sequences of motile strains of $Y$. ruckeri have been annotated and can now be used for comparative genomic analysis of $Y$. ruckeri strains, investigation of gene-level pathogenicity, development of potential drug targets and vaccines. Quantitative proteomic analysis of multiple geographic isolates of biotypes 1 and 2 Y. ruckeri strains are not yet completed, and are required to create a proteomic map and understand proteomic changes and differences between the biotypes and strains. Some potential virulence factors of $Y$. ruckeri have been identified but more research on the bacterium's virulence mechanisms is needed to understand the full pathogenicity of $Y$. ruckeri during the course of infection. Investigations have revealed aspects of the fish immune response to $Y$. ruckeri infections, however there is still an urgent need to improve our understanding of the biochemical changes that occur in host tissues and organs during infection. Biotype 2 strains of $Y$. ruckeri have been responsible for outbreaks in rainbow trout that had been vaccinated against biotype 1 , thereby confirming the failure of monovalent vaccines to protect the fish against infection. Formalin inactivated bivalent vaccines can significantly reduce mortalities due to infections with biotype 2 strains but the development of more efficient vaccines against both biotypes of $Y$. ruckeri is still needed. 


\section{Abbreviations}

CDNA: Complementary DNA; CDS: Coding sequences; CISH: Cytokineinducible SH2-containing protein; dpe: Days post exposure; ECP: Extra-cellular product; ERIC-PCR: Enterobacterial repetitive intergenic consensus sequence-based PCR; ERM: Enteric redmouth, HSF: Heat sensitive factor; LAMP: Loop-mediated isothermal amplification; MLST: Multilocus sequence typing; mpi: Minute post infection; PCR: Polymerase chain reaction; PFGE: Pulsed-field gel electrophoresis; qPCR: Quantitative PCR; SCOS: Suppressor of cytokine signaling; Y. ruckeri: Yersinia ruckeri.

\section{Competing interests}

The authors declare that they have no competing interests.

\section{Authors' contributions}

GK designed the structure of review and took the lead in drafting the manuscript and prepared the figures and tables. SML wrote the virulence factors, antibiotherapy and probiotics sections and MS wrote the transmission and diagnosis sections. MEL helped with the revision of the draft. All authors read and approved the final manuscript.

\section{Acknowledgements}

This study was funded by the Austrian Science Fund (FWF) project no. P 27489-B22. We are thankful to Dr Stephen Atkinson for language editorial input to the manuscript.

\section{Received: 2 April 2015 Accepted: 11 August 2015 Published online: 24 September 2015}

\section{References}

1. FAO (2010) The state of world fisheries and aquaculture. Food and Agriculture Organization of the United Nations, Rome

2. Horne MT, Barnes AC (1999) Enteric redmouth disease (Yersinia ruckeri) In: Woo PTK, Bruno DW (eds) Fish diseases and disorders. Viral, bacterial and fungal infections. CABI Publishing, Wallingford, pp 445-477

3. Ross AJ, Rucker RR, Ewing WH (1966) Description of a bacterium associated with redmouth disease of rainbow trout (Salmo gairdneri). Can J Microbiol 12:763-770

4. Tobback E, Decostere A, Hermans K, Haesebrouck F, Chiers K (2007) Yersinia ruckeri infections in salmonid fish. J Fish Dis 30:257-268

5. Shaowu L, Di W, Hongbai L, Tongyan L (2013) Isolation of Yersinia ruckeri strain $\mathrm{H} 01$ from farm-raised amur sturgeon Acipenser schrencki in China. J Aquat Anim Health 25:9-14

6. Ewing EW, Ross AJ, Brenner DJ, Fanning GR (1978) Yersinia ruckeri sp. nov., the redmouth (RM) bacterium. Int J Syst Bacteriol 28:37-44

7. Navas $E$, Bohle $H$, Henríquez $P$, Grothusen $H$, Bustamante F, Bustos $P$, Mancilla M (2014) Draft genome sequence of the fish pathogen Yersinia ruckeri strain 37551, serotype $01 \mathrm{~b}$, isolated from diseased, vaccinated Atlantic salmon (Salmo salar) in Chile. Genome Announc 2:e0085-14

8. Daligault HE, Davenport KW, Minogue TD, Bishop-Lilly KA, Broomall SM, Bruce DC, Chain PS, Coyne SR, Frey KG, Gibbons HS, Jaissle J, Koroleva GI, Ladner JT, Lo CC, Munk C, Palacios GF, Redden CL, Rosenzweig CN, Scholz MB, Johnson SL (2014) Whole-genome Yersinia sp. assemblies from 10 diverse strains. Genome Announc 2:e01055-14

9. Chen PE, Cook C, Stewart AC, Nagarajan N, Sommer DD, Pop M, Thomason B, Thomason MP, Lentz S, Nolan N, Sozhamannan S, Sulakvelidze A, Mateczun A, Du L, Zwick ME, Read TD (2010) Genomic characterization of the Yersinia genus. Genome Biol 11:R1

10. Romalde JL, Toranzo AE (1993) Pathological activities of Yersinia ruckeri, the enteric redmouth (ERM) bacterium. FEMS Microbiol Lett 112:291-300

11. Evenhuis JP, Lapatra SE, Verner-Jeffreys DW, Dalsgaard I, Welch TJ (2009) Identification of flagellar motility genes in Yersinia ruckeri by transposon mutagenesis. Appl Environ Microbiol 75:6630-6633

12. Schill WB, Phelps SR, Pyle SW (1984) Multilocus electrophoretic assessment of the genetic structure and diversity of Yersinia ruckeri. Appl Environ Microbiol 48:975-979

13. Huang Y, Runge M, Michael GB, Schwarz S, Jung A, Steinhagen D (2013) Biochemical and molecular heterogeneity among isolates of Yersinia ruckeri from rainbow trout (Oncorhynchus mykiss, Walbaum) in North West Germany. BMC Vet Res 9:215
14. Bastardo A, Ravelo C, Romalde JL (2012) Multilocus sequence typing reveals high genetic diversity and epidemic population structure for the fish pathogen Yersinia ruckeri. Environ Microbiol 14:1888-1897

15. Arias CR, Olivares-Fuster O, Hayden K, Shoemaker CA, Grizzle JM, Klesius PH (2007) First report of Yersinia ruckeri biotype 2 in the U.S.A. J Aquat Anim Health 19:35-40

16. Tinsley JW, Lyndon AR, Austin B (2011) Antigenic and cross-protection studies of biotype 1 and biotype 2 isolates of Yersinia ruckeri in rainbow trout, Oncorhynchus mykiss (Walbaum). J Appl Microbiol 111:8-16

17. Welch TJ (2011) Rapid genotyping assays for the identification and differentiation of Yersinia ruckeri biotype 2 strains. Lett Appl Microbiol 53:383-385

18. Tobback E, Decostere A, Hermans K, Ryckaert J, Duchateau L, Haesebrouck F, Chiers K (2009) Route of entry and tissue distribution of Yersinia ruckeri in experimentally infected rainbow trout Oncorhynchus mykiss. Dis Aquat Org 84:219-228

19. Manna SK, Samanta S, Das MK, Mishra SS (2003) An outbreak of Yersinia ruckeri septicemia in Indian major carps. J Inland Fish Soc India 35:28-31

20. Willumsen B (1989) Birds and wild fish as potential vectors of Yersinia ruckeri. J Fish Dis 12:275-277

21. Farmer JJ 3rd, Davis BR, Hickman-Brenner FW, McWhorter A, Huntley-Carter GP, Asbury MA, Riddle C, Wathen-Grady HG, Elias C, Fanning GR (1985) Biochemical identification of new species and biogroups of Enterobacteriaceae isolated from clinical specimens. J Clin Microbiol 21:46-76

22. Rodgers CJ (1992) Development of a selective-differential medium for the isolation of Yersinia ruckeri and its application in epidemiological studies. J Fish Dis 15:243-254

23. Busch RA, Lingg AJ (1975) Establishment of an asymptomatic carrier state infection of enteric redmouth disease in rainbow trout (Salmo gairdneri). J Fish Res Board Can 32:2429-2432

24. Hunter VA, Knittel MD, Fryer JL (1980) Stress-induced transmission of Yersinia-ruckeri infection from carriers to recipient steelhead trout Salmogairdneri richardson. J Fish Dis 3:467-472

25. O'Toole GA, Kolter R (1998) Flagellar and twitc hing motility are necessary for Pseudomonas aeruginosa biofilm development. Mol Microbiol 30:295-304

26. Pratt LA, Kolter R (1998) Genetic analysis of Escherichia coli biofilm formation: roles of flagella, motility, chemotaxis and type I pili. Mol Microbiol 30:285-293

27. Coquet L, Cosette P, Junter GA, Beucher E, Saiter JM, Jouenne T (2002) Adhesion of Yersinia ruckeri to fish farm materials: influence of cell and material surface properties. Colloids Surf B: Biointerfaces 26:373-378

28. Glenn RA, Taylor PW, Pelton EH, Gutenberger SK, Ahrens MA, Marchant LM, Hanson KC (2014) Genetic evidence of vertical transmission and cycling of Yersinia ruckeri in hatchery-origin fall chinook salmon Oncorhynchus tshawytscha. J Fish Wildl Manage 5:197

29. Ohtani M, Villumsen KR, Strøm HK, Raida MK (2014) 3D Visualization of the initial Yersinia ruckeri infection route in rainbow trout (Oncorhynchus mykiss) by optical projection tomography. PLoS One 9:e89672

30. Nelson MC, LaPatra SE, Welch TJ, Graf J (2015) Complete genome sequence of Yersinia ruckeri strain CSF007-82, etiologic agent of red mouth disease in salmonid fish. Genome Announc 3:e01491-14

31. Austin DA, Robertson PAW, Austin B (2003) Recovery of a new biogroup of Yersinia ruckeri from diseased rainbow trout (Oncorhynchus mykiss, Walbaum). Syst Appl Microbiol 26:127-131

32. Gibello A, Blanco MM, Moreno MA, Cutuli MT, Domenech A, Domínguez L, Fernández-Garayzábal JF (1999) Development of a PCR assay for detection of Yersinia ruckeri in tissues of inoculated and naturally infected trout. Appl Environ Microbiol 65:346-350

33. Smith AM, Goldring OL, Dear G (1987) The production and methods of use of polyclonal antisera to the pathogenic organisms Aeromonas salmonicida, Yersinia ruckeri and Renibacterium salmoninarum. J Fish Biol 31:225-226

34. Garcia JA, Dominguez L, Larsen JL, Pedersen K (1998) Ribotyping and plasmid profiling of Yersinia ruckeri. J Appl Microbiol 85:949-955

35. Saleh M, Soliman H, El-Matbouli M (2008) Loop-mediated isothermal amplification as an emerging technology for detection of Yersinia ruckeri the causative agent of enteric red mouth disease in fish. BMC Vet Res 4:31

36. Lejeune JR, Rurangirwa FR (2000) Polymerase chain reaction for definitive identification of Yersinia ruckeri. J Vet Diagn Investig 12:558-561

37. Altinok I, Grizzle JM, Liu Z (2001) Detection of Yersinia ruckeri in rainbow trout blood by use of the polymerase chain reaction. Dis Aquat Org 44:29-34

38. Noga E, Levine JF, Townsend K, Bullis RA, Carlson CP, Corbett WT (1988) Kidney biopsy: a nonlethal method for diagnosing Yersinia ruckeri infection (enteric redmouth disease) in rainbow trout Salmo gairdneri. Am J Vet Res 49:363-365 
39. Glenn RA, Taylor PW, Hanson KC (2011) The use of a real-time PCR primer/ probe set to observe infectivity of Yersinia ruckeri in Chinook salmon, Oncorhynchus tshawytscha (Walbaum), and steelhead trout, Oncorhynchus mykiss (Walbaum). J Fish Dis 34:783-791

40. Keeling SE, Johnston C, Wallis R, Brosnahan CL, Gudkovs N, McDonald WL (2011) Development and validation of real-time PCR for the detection of Yersinia ruckeri. J Fish Dis 35:119-125

41. Temprano A, Yugueros J, Hernanz C, Sánchez M, Berzal B, Luengo JM, Naharro G (2001) Rapid identification of Yersinia ruckeri by PCR amplification of yrul-yruR quorum sensing. J Fish Dis 24:253-261

42. Bastardo A, Ravelo C, Romalde JL (2012) Highly sensitive detection and quantification of the pathogen Yersinia ruckeri in fish tissues by using realtime PCR. Appl Microbiol Biotechnol 96:511-520

43. Saleh M, Soliman H, El-Matbouli M (2015) Gold nanoparticles as a potential tool for diagnosis of fish diseases. Methods Mol Biol 1247:245-252

44. Fernández L, Prieto M, Guijarro J (2007) The iron- and temperatureregulated haemolysin YhIA is a virulence factor of Yersinia ruckeri. Microbiology 153:483-489

45. Secades P, Guijarro JA (1999) Purification and characterization of an extracellular protease from the fish pathogen Yersinia ruckeri and effect of culture conditions on production. Appl Environ Microbiol 65:3969-3975

46. Fernandez L, Lopez JR, Secades P, Menendez A, Marquez I, Guijarro JA (2003) In vitro and in vivo studies of the Yrp1 protease from Yersinia ruckeri and its role in protective immunity against enteric red mouth disease of salmonids. Appl Environ Microbiol 69:7328-7335

47. Fernández L, Secades P, Lopez JR, Márquez I, Guijarro JA (2002) Isolation and analysis of a protease gene with an $A B C$ transport system in the fish pathogen Yersinia ruckeri: Insertional mutagenesis and involvement in virulence. Microbiology 148:2233-2243

48. Navais R, Méndez J, Pérez-Pascual D, Cascales D, Guijarro JA (2014) The yrpAB operon of Yersinia ruckeri encoding two putative U32 peptidases is involved in virulence and induced under microaerobic conditions. Virulence 5:619-624

49. Fernández L, Márquez I, Guijarro JA (2004) Identification of specific in vivoinduced (ivi) genes in Yersinia ruckeri and analysis of ruckerbactin, a catecholate siderophore iron acquisition system. Appl Environ Microbiol 70:5199-5207

50. Furones MD, Gilpin MJ, Alderman DJ, Munn CB (1990) Virulence of Yersinia ruckeri serotype I strains is associated with a heat sensitive factor (HSF) in cell extracts. FEMS Microbiol Lett 66:339-344

51. Furones MD, Gilpin ML, Munn CB (1993) Culture media for the differentiation of isolates of Yersinia ruckeri, based on detection of a virulence factor. J Appl Microbiol 74:360-366

52. Navais R, Méndez J, Cascales D, Reimundo P, Guijarro JA (2014) The heat sensitive factor (HSF) of Yersinia ruckeri is produced by an alkyl sulphatase involved in sodium dodecyl sulphate (SDS) degradation but not in virulence. BMC Microbiol 14:221

53. Méndez J, Reimundo P, Pérez-Pascual D, Navais R, Gómez E, Guijarro JA (2011) A novel $c d s A B$ operon is involved in the uptake of $L$-cysteine and participates in the pathogenesis of Yersinia ruckeri. J Bacteriol 193:944-951

54. Navais R, Méndez J, Reimundo P, Pérez-Pascual D, Gómez E, Guijarro JA (2011) The yctCBA operon of Yersinia ruckeri, involved in in vivo citrate uptake, is not required for virulence. Appl Environ Microbiol 77:1107-1110

55. Kastbjerg VG, Nielsen KF, Dalsgaard I, Rasch M, Bruhn JB, Givskov M, Gram L (2007) Profiling acylated homoserine lactones in Yersinia ruckeri and influence of exogenous acyl homoserine lactones and known quorumsensing inhibitors on protease production. J Appl Microbiol 102:363-374

56. Dahiya I, Stevenson RMW (2010) The UvrY response regulator of the BarAUvrY two-component system contributes to Yersinia ruckeri infection of rainbow trout (Oncorhynchus mykiss). Arch Microbiol 192:541-547

57. Anderson DP, Dixon OW, Roberson BS (1979) Kinetics of the primary immune response in rainbow trout after flush exposure to Yersinia ruckeri Oantigen. Dev Comp Immunol 3:739-744

58. Cossarini-Dunier M (1986) Secondary response of rainbow trout to DNPhaemocyanin and Y. ruckeri. Aquaculture 52:81-86

59. Afonso A, Lousada S, Silva J, Ellis AE, Silva MT (1998) Neutrophil and macrophage responses to inflammation in the peritoneal cavity of rainbow trout Oncorhynchus mykiss. A light and electron microscopic cytochemical study. Dis Aquat Organ 34:27-37

60. Wiens GD, Glenney GW, LaPatra SE, Welch TJ (2006) Identification of novel rainbow trout (Oncorhynchus mykiss) chemokines, CXCd1 and CXCd2: mRNA expression after Yersinia ruckeri vaccination and challenge. Immunogenetics 58:308-323
61. Raida MK, Buchmann K (2009) Innate immune response in rainbow trout (Oncorhynchus mykiss) against primary and secondary infections with Yersinia ruckeri 01. Dev Com Immunol 33:35-45

62. Harun NO, Wang T, Secombes CJ (2011) Gene expression profiling in naïve and vaccinated rainbow trout after Yersinia ruckeri infection: Insights into the mechanisms of protection seen in vaccinated fish. Vaccine 29:4388-4399

63. Raida MK, Nylén J, Holten-Andersen L, Buchmann K (2011) Association between plasma antibody response and protection in rainbow trout Oncorhynchus mykiss immersion vaccinated against Yersinia ruckeri. PLoS One 6:e18832

64. Chettri JK, Raida MK, Kania PW, Buchmann K (2012) Differential immune response of rainbow trout (Oncorhynchus mykiss) at early developmental stages (larvae and fry) against the bacterial pathogen Yersinia ruckeri. Dev Comp Immunol 36:463-474

65. Wiens GD, Vallejo RL (2010) Temporal and pathogen-load dependent changes in rainbow trout (Oncorhynchus mykiss) immune response traits following challenge with biotype 2 Yersinia ruckeri. Fish Shellfish Immunol 29:639-647

66. Evenhuis JP, Cleveland BM (2012) Modulation of rainbow trout (Oncorhynchus mykiss) intestinal immune gene expression following bacterial challenge. Fish Shellfish Immunol 146:8-17

67. Kania PW, Chettri JK, Buchmann K (2014) Characterization of serum amyloid $A(S A A)$ in rainbow trout using a new monoclonal antibody. Fish Shellfish Immunol 40:648-658

68. Paulson L, Martin P, Persson A, Nilsson CL, Ljung E, Westman-Brinkmalm A, Eriksson PS, Blennow K, Davidsson P (2003) Comparative genome and proteome analysis of cerebral cortex from MK-801-treated rats. J Neurosci 71:526-533

69. Alderman DJ, Hastings TS (1998) Antibiotic use in aquaculture: development of antibiotic resistance - potential for consumer health risks. Int J Food Sci Technol 33:139-155

70. Michel C, Kerouault B, Martin C (2003) Chloramphenicol and florfenicol susceptibility of fish-pathogenic bacteria isolated in France: Comparison of minimum inhibitory concentration, using recommended provisory standards for fish bacteria. J Appl Microbiol 95:1008-1015

71. Defoirdt T, Boon N, Sorgeloos P, Verstraete W, Bossier P (2007) Alternatives to antibiotics to control bacterial infections: luminescent vibriosis in aquaculture as an example. Trends Biotechnol 25:472-479

72. Calvez S, Gantelet H, Blanc G, Douet DG, Daniel P (2014) Yersinia ruckeri biotypes 1 and 2 in France: presence and antibiotic susceptibility. Dis Aquat Org 109:117-126

73. Mammeri H, Poirel L, Nazik H, Nordmann P (2006) Cloning and functional characterization of the ambler class $C$ beta-lactamase of Yersinia ruckeri. FEMS Microbiol Lett 257:57-62

74. Stock I, Henrichfreise B, Wiedemann B (2002) Natural antibiotic susceptibility and biochemical profiles of Yersinia enterocolitica-like strains: Y. bercovieri, $Y$. mollaretii, Y. aldovae and "Y. ruckeri.". J Med Microbiol 51:56-69

75. Rodgers CJ (2001) Resistance of Yersinia ruckeri to antimicrobial agents in vitro. Aquaculture 196:325-345

76. Qin Z, Baker AT, Raab A, Huang S, Wang T, Yu Y, Jaspars M, Secombes CJ, Deng $H$ (2013) The fish pathogen Yersinia ruckeri produces holomycin and uses an RNA methyltransferase for self-resistance. J Biol Chem 288:14688-14697

77. Irianto A, Austin B (2002) Probiotics in aquaculture. J Fish Dis 25:633-642

78. Raida MK, Larsen JL, Nielsen ME, Buchmann K (2003) Enhanced resistance of rainbow trout, Oncorhynchus mykiss (Walbaum), against Yersinia ruckeri challenge following oral administration of Bacillus subtilis and B. licheniformis (BioPlus2B). J Fish Dis 26:495-498

79. Abbass A, Sharifuzzaman SM, Austin B (2010) Cellular components of probiotics control Yersinia ruckeri infection in rainbow trout, Oncorhynchus mykiss (Walbaum). J Fish Dis 33:31-37

80. Brunt J, Newaj-Fyzul A, Austin B (2007) The development of probiotics for the control of multiple bacterial diseases of rainbow trout, Oncorhynchus mykiss (Walbaum). J Fish Dis 30:573-579

81. Capkin E, Altinok I (2009) Effects of dietary probiotic supplementations on prevention/treatment of yersiniosis disease. J Appl Microbiol 106:1147-1153

82. Kim DH, Austin B (2006) Innate immune responses in rainbow trout (Oncorhynchus mykiss, Walbaum) induced by probiotics. Fish Shellfish Immunol 21:513-524

83. Robertson PAW, O'Dowd C, Burrells C, Williams P, Austin B (2000) Use of Carnobacterium sp. as a probiotic for Atlantic salmon (Salmo salar L.) and rainbow trout (Oncorhynchus mykiss, Walbaum). Aquaculture 185:235-243

84. Balcázar JL, Vendrell D, de Blas I, Ruiz-Zarzuela I, Muzquiz JL, Girones O (2008) Characterization of probiotic properties of lactic acid bacteria isolated from intestinal microbiota of fish. Aquaculture 278:188-191 
85. Sica MG, Brugnoni LI, Marucci PL, Cubitto MA (2012) Characterization of probiotic properties of lactic acid bacteria isolated from an estuarine environment for application in rainbow trout (Oncorhynchus mykiss, Walbaum) farming. Antonie Van Leeuwenhoek 101:869-879

86. Ingerslev HC, Strube ML, Jørgensen LVG, Dalsgaard I, Boye M, Madsen L (2014) Diet type dictates the gut microbiota and the immune response against Yersinia ruckeri in rainbow trout (Oncorhynchus mykiss). Fish Shellfish Immunol 40:624-633

87. Jaafar RM, Kania PW, Larsen AH, Nielsen DS, Fouz B, Browdy C, Buchmann K (2012) Gut microbiota changes in rainbow trout, Oncorhynchus mykiss (Walbaum), during organic acid feed supplementation and Yersinia ruckeri infection. J Fish Dis 36:599-606

88. Busch RA (1978) Protective vaccines for mass immunization of trout. Salmonid 1:10-22

89. Cagirgan H, Tanrikul T (1998) Testing the effectiveness of a Yersinia ruckeri in infected and chemically treated juvenile rainbow trout (Oncorhynchus mykiss). J Appl Ichthyol 14:239-243

90. Raida MK, Buchmann K (2008) Bath vaccination of rainbow trout (Oncorhynchus mykiss Walbaum) against Yersinia ruckeri: effects of temperature on protection and gene expression. Vaccine 26:1050-1062

91. Costa AA, Leef MJ, Bridle AR, Carson J, Nowak BF (2011) Effect of vaccination against yersiniosis on the relative percent survival, bactericidal and lysozyme response of Atlantic salmon, Salmo salar. Aquaculture 315:201-206

92. Soltani M, Shafiei S, Yosefi P, Mosavi S, Mokhtari A (2014) Effect of

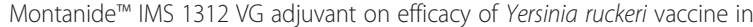
rainbow trout (Oncorhynchus mykiss). Fish Shellfish Immunol 37:60-65

93. Villumsen KR, Neumann L, Ohtani M, Strøm HK, Raida MK (2014) Oral and anal vaccination confers full protection against enteric redmouth disease (ERM) in rainbow trout. PLoS One 9:e93845

94. Temprano A, Riano J, Yugueros J, Gonzalez P, de Castro L, Villena A, Luengo JM, Naharro G (2005) Potential use of a Yersinia ruckeri $\mathrm{O} 1$ auxotrophic aroA mutant as a live attenuated vaccine. J Fish Dis 28:419-427

95. Ispir U, Dorucu M (2010) Effect of immersion booster vaccination with Yersinia ruckeri extracellular products (ECP) on rainbow trout Oncorhynchus mykiss. Int Aquat Res 2:127-130

96. Ispir U, Dorucu M (2014) Efficacy of lipopolysaccharide antigen of Yersinia ruckeri in rainbow trout by intraperitoneal and bath immersion administration. Res Vet Sci 97:271-273

97. Deshmukh S, Raida MK, Dalsgaard I, Chettri JK, Kania PW, Buchmann K (2012) Comparative protection of two different commercial vaccines against Yersinia ruckeri serotype $\mathrm{O} 1$ and biotype 2 in rainbow trout (Oncorhynchus mykiss). Vet Immunol Immunopathol 145:379-385

98. Bridle AR, Koop BF, Nowak BF (2012) Identification of surrogates of protection against yersiniosis in immersion vaccinated Atlantic salmon. PLoS One 7:e40841

99. Scott CJ, Austin B, Austin DA, Morris PC (2013) Non-adjuvanted flagellin elicits a non-specific protective immune response in rainbow trout (Oncorhynchus mykiss, Walbaum) towards bacterial infections. Vaccine 31:3262-3267

\section{Submit your next manuscript to BioMed Central and take full advantage of:}

- Convenient online submission

- Thorough peer review

- No space constraints or color figure charges

- Immediate publication on acceptance

- Inclusion in PubMed, CAS, Scopus and Google Scholar

- Research which is freely available for redistribution

Submit your manuscript at www.biomedcentral.com/submit 